\title{
Heart Valve Clinic: A Model for Treatment of Structural Heart Disease
}

\author{
Kendal Endicott' ${ }^{1}$, Jacob Lambdin'1, Jason Morrisette', Amy Kirkpatrick ${ }^{1}$, Christian Nagy ${ }^{1}$, \\ Frederick Mordini' ${ }^{1}$, Michael Greenberg', Gregory Trachiotis ${ }^{1,2 *}$ \\ ${ }^{1}$ Division of Cardiology and Cardiothoracic Surgery, The Heart Center, Washington DC Veterans Affairs Medical Center, \\ Washington DC, USA \\ ${ }^{2}$ The George Washington University, Washington DC, USA \\ Email: ^gregory.trachiotis@va.gov
}

How to cite this paper: Endicott, K., Lambdin, J., Morrisette, J., Kirkpatrick, A., Nagy, C., Mordini, F., Greenberg, M. and Trachiotis, G. (2017) Heart Valve Clinic: A Model for Treatment of Structural Heart Disease. World Journal of Cardiovascular Surgery, 7, 1-9.

http://dx.doi.org/10.4236/wjcs.2017.71001

Received: October 27, 2016

Accepted: January 7, 2017

Published: January 10, 2017

Copyright (c) 2017 by authors and Scientific Research Publishing Inc. This work is licensed under the Creative Commons Attribution International License (CC BY 4.0).

http://creativecommons.org/licenses/by/4.0/

\begin{abstract}
Background and Aim of the Study: Valvular heart disease (VHD) should be managed by a Heart Valve Team (HVT) for optimal treatment. Although the prevalence of VHD is increasing, an overall lack of universal implementation of the HVT continues to exist. Here we present our model of care within a Veteran's Affairs Medical Center (VAMC). Materials and Methods: All patients referred to our VAMC with structural valvular disease have been managed within our multidisciplinary heart valve clinic since 2006. The heart valve clinic consists of a dedicated valve surgeon as well as both a dedicated noninvasive imaging cardiologist and cardiac MRI/CT cardiologist. Cases are reviewed on a weekly basis with multidisciplinary input to guide treatment strategy. Therapy includes medical management, facilitation of further diagnostic workup, and referral for operative intervention. Results: Between 2006 and 2015, 560 patients have been evaluated in HVC. Overall, new patient yearly volume has nearly tripled with now over 90 new consults seen yearly. Of the patients evaluated, 313 were referred for operative intervention with follow up post-operatively to affirm adequate post-procedural function. Following HVC referral trends, operative yearly volume has increased $33 \%$ over the last year years compared to the first three years of the program. The heart valve clinic has also matured to support a dedicated TAVR program. Conclusions: As the options for heart valve therapy and indications for surgery continue to evolve, a multidisciplinary team to guide decision making is imperative. We present the success and growth of our heart valve clinic within a VAMC as a structural model that can be translated into both the community and academic setting.
\end{abstract}

\section{Keywords}

Acquired Disease, Valve Replacement 


\section{Introduction}

Structural valvular heart disease (VHD) should be treated by an integrated team of medical and surgical subspecialties. The need for coordination has become increasingly important with the advent of transcatheter valve placement (TVR) allowing otherwise prohibitive surgical candidates the opportunity for valve replacement. Though defined guidelines for operative intervention exist, the timing, strategy, and suitability of intervention must be individualized for each patient as referral for operative intervention has become a complex algorithm of decision making involving various imaging modalities, longitudinal patient care, and optimization of medical therapy.

The American College of Cardiology and American Heart Association Task Force in addition to the European Society of Cardiology (ESC) and the European Association for Cardio-Thoracic Surgery (EACTS) guidelines suggest the concept of a Heart Valve Team (HVT) for optimal management of patents with VHD [1] [2]. Ideally, the HVT manages VHD from presentation to prevent the often silent clinical progression to irreversible disease. With continual consideration of both medical and surgical factors, VHD patients can undergo appropriate intervention when surgery carries lower risk and is more effective in improving survival outcomes [3].

With the ongoing expansion of TVR options and new technology, the use of a HVT to guide therapy is highlighted in a statement from the Society of Thoracic Surgeons (STS) [4]. The heart valvecenter is described as the ideal venue for TVR expansion to serve as "guardrails" in the face of new technology. Pre-procedure evaluation by a multidisciplinary team conference, valvular heart disease clinics, and joint performance of the procedure and post-operative care are discussed as essential elements of a successful TVR team.

Though the recommendations to implement multidisciplinary care and follow up to guide management of VHD are clear, little has been described in the literature regarding the structure and implementation of the Heart Valve Clinic (HVC). As a VA referral center for the surgical treatment of valve disease, our center has been afforded the opportunity to centralize care of VHD within a specialized HVT. As a diverse, complex, and rigorously tracked and monitored population, the VA health system presents an optimal setting for implementation of the HVC. Herein, we discuss the structure, success, and growth of our HVC within a Veteran's Affairs Medical Center (VAMC) at a regional referral center as a model for the treatment of valvular heart disease in the era of TVR therapy.

\section{Methods}

\subsection{Goals of the Heart Valve Clinic}

The overarching goal of the HVC at our institution is to provide multidisciplinary, timely management of VHD. Our designation as a Veteran's Affairs Hospital regional referral center allows for centralized care with excellent continuity 
to help prevent the potential serious consequences of VHD patients "lost to follow up." This goal is facilitated in four phases 1) Proactive, preemptive identification of patients with moderate to severe valvular disease 2) Initial assessment 3) Interim assessment, and 4) Long term follow-up (Table 1).

Upon referral, initial objectives include a complete medical assessment delineating of the extent and severity of the structural valvular disease. The need for initial imaging (discussed in detail later) is facilitated in addition to management of heart failure and blood pressure medications. Interim assessment goals which are facilitated in follow up clinic visits and Heart Valve Conference include discussion regarding appropriate surgical referral, patient education, and follow up imaging and referral for additional medical resources as needed for medical optimization. Long term objectives include optimization of surgical intervention in those patients who are followed in our HVC as well as a decrease in the overall VHD health care related costs from hospital admissions and delayed care.

\subsection{Patient Selection}

As a tertiary referral center for cardiac surgery in a wide geographic region, the referral base is diverse and presents from multiple venues. Patients appropriate for referral include those with moderate to severe valvular dysfunction that may benefit from intervention, adult congenital heart disease, aortic pathology, bicuspid aortic valves in the context of connective tissue disorder, and those with structural pathologies (i.e. ASD, PFO, and VSD). Cases of mild valvular disease are not referred for further assessment in our clinic however communication is made with the referring physician to ensure appropriate interval echocardiographic follow up to detect disease progression.

\subsection{Referral, Initial Workup, and Follow-Up}

As the regional heart valve clinic for the area, the first notable set of referrals is initiated outside our institution. After reviewing patient records from the referring institution to affirm the appropriateness of the referral, patients are seen for

Table 1. Objectives of the HVC.

\begin{tabular}{|c|c|c|}
\hline Initial assessment & Interim assessment & Long term follow up \\
\hline $\begin{array}{l}\text { Define degree and } \\
\text { severity of VHD }\end{array}$ & $\begin{array}{c}\text { Define need for surgical } \\
\text { intervention }\end{array}$ & $\begin{array}{l}\text { Optimize timing of surgical } \\
\text { intervention }\end{array}$ \\
\hline $\begin{array}{l}\text { Facilitate appropriate } \\
\text { initial imaging }\end{array}$ & Patient education & $\begin{array}{l}\text { Decrease overall VHD } \\
\text { health-care related costs }\end{array}$ \\
\hline $\begin{array}{c}\text { Management of key } \\
\text { cardiovascular comorbidities } \\
\text { (i.e. heart failure and blood } \\
\text { pressure medications) }\end{array}$ & $\begin{array}{l}\text { Referral for appropriate } \\
\text { adjuvant resources and } \\
\text { primary care follow-up }\end{array}$ & $\begin{array}{l}\text { Reduce VHD related hospital } \\
\text { admission, morbidity, } \\
\text { and mortality }\end{array}$ \\
\hline & ollow up imaging as needed & \\
\hline
\end{tabular}

*Includes dedicated diabetes clinic, blood pressure control medications (B-blocker, ACE or ARB as indicated), aspirin or dual-antiplatelet therapy use as indicated, smoking cessation counseling, and cardiopulmonary rehab as indicated. 
an initial assessment. Echocardiography (ECHO) is performed in house to obtain a real-time, baseline assessment of structure and function. These initial visits are coordinated within our HVT which consists of physician extenders, dedicated echocardiography nurses, and cardiologists with early involvement of cardiothoracic surgery. After initial evaluation, diagnosis can be established with a diagnostic management plan in mind. Patients return to clinic to discuss this plan and initiate further diagnostic steps.

For patients deemed to meet criteria for possible operative intervention, patients undergo appropriate diagnostic workup with subsequent presentation in our multidisciplinary heart valve conference within three to six months of initial visit. With both our cardiology and cardiac surgery teams present, each patient case is reviewed for need for operative intervention. Any further diagnostic questions are further pursued after which the patient is scheduled for surgery if deemed appropriate. TVR candidates are reviewed rigorously by our dedicated team led by a structural interventionalist cardiologist.

Post-operatively, patients are followed in the cardiothoracic clinic and heart valve clinic with repeat ECHO. If post-operative ECHO is without structural concerns, patients are then transitioned back to their local primary care doctor for ongoing surveillance and management of medical care. For patients who do not meet criteria for operative intervention, appropriate follow up is initiated at 1 month, 3 months, 6 months or a year according to guidelines based on severity of disease. Follow up is managed by a nurse coordinator to ensure return to clinic appointments and feedback to referring physicians. Any patients with clinical uncertainties or borderline criteria for operative intervention are presented periodically in heart valve conference to follow changes and reassess the need for operative intervention.

In addition to outside institution referrals, patients are referred from within our hospital from primary care clinics, within cardiology, by the cardiothoracic team, and also by our those cardiologists who specialize in ECHO (Figure 1). If patients are found to have VHD, an inquiry is made back to the referring provider to recommend referral to our HVC.

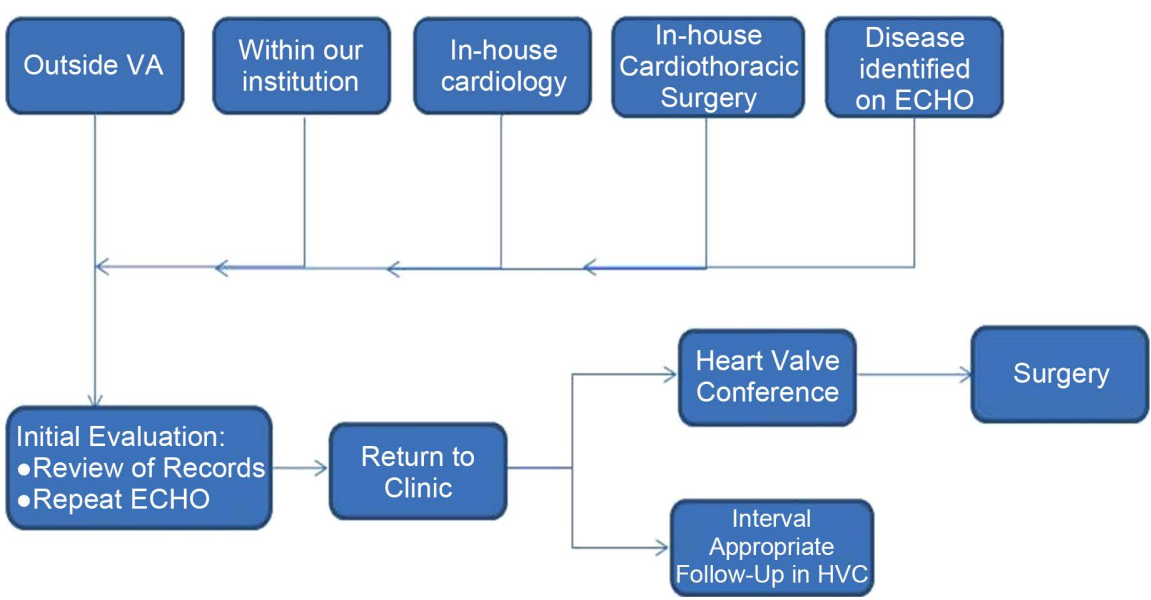

Figure 1. Structure of referral base to HVC and subsequent follow up. 


\subsection{Imaging Modalities}

The cornerstone of management of VHD is cardiac imaging. As such, our HVC and conference include a dedicated noninvasive imaging team, cardiac MRI/CT cardiologist, and dedicated valve surgeon. During Heart Valve Conference, all cardiac images with comparison to previous studies are reviewed to facilitate decision making and the need for further imaging. Table 2 outlines a detailed algorithm for imaging in patients who present to HVC with aortic and mitral valvular disease.

Table 2. Detailed description of the utilization of various imaging modalities in aortic and mitral valvular disease within our HVC.

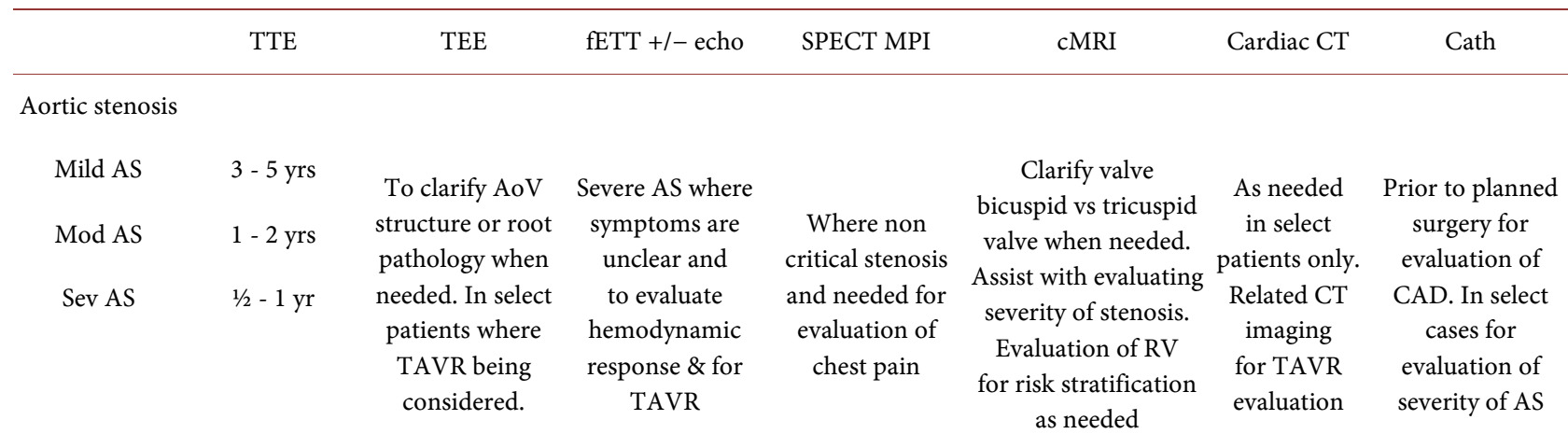

Aortic regurg

\begin{tabular}{|c|c|c|}
\hline Mild AR & $3-5$ yrs & In severe $\mathrm{AR}$ \\
\hline Mod AR & $1-2 \mathrm{yrs}$ & $\begin{array}{l}\text { and to clarify } \\
\text { coexistent root }\end{array}$ \\
\hline Sev AR & $1 / 2-1 y r$ & $\begin{array}{l}\text { pathology or } \\
\text { valve structure }\end{array}$ \\
\hline
\end{tabular}

Severe AI where When needed symptoms are for evaluation unclear of chest pain

Mitral stenosis

$\begin{array}{ll}\text { Mild MS } & 3-5 \mathrm{yrs} \\ \text { Mod MS } & 1-2 \mathrm{yrs} \\ \text { Sev MS } & 1 / 2-1 \mathrm{yr}\end{array}$

Mitral regurg

$\begin{array}{ll}\text { Mild MR } & 3-5 \mathrm{yrs} \\ \text { Mod MR } & 1-2 \mathrm{yrs} \\ \text { Sev MR } & 1 / 2-1 \mathrm{yr}\end{array}$

*Every 3 months when dilated

As needed in select patients

As needed to clarify symptoms and response to exercise

When needed for evaluation of chest pain
As needed in select patients only

As needed for clarification of bicuspid vs tricuspid. As needed to follow chamber volumes and EF once severe

$$
\begin{array}{cc}
\text { As needed } & \begin{array}{c}
\text { Prior to planned } \\
\text { in select }
\end{array} \\
\begin{array}{c}
\text { surgery for } \\
\text { evaluation }
\end{array} \\
\text { patients only } & \text { of CAD }
\end{array}
$$

Prior to planned surgery for evaluation of CAD

\section{As needed in Prior to planned}

select patients surgery for only of CAD
As needed for mod-severe when mod-sev to clarify symptoms and at times changes in pulmonary pressures
When needed for evaluation of chest pain regurgitation for evaluation of RV function and serial changes in LV function structural etiolog and assist with surgical planning

Abbreviations: Sev $=$ Severe, AS = Aortic Stenosis, AR = Aortic Regurgitation, $\mathrm{MS}=$ Mitral Stenosis, $\mathrm{MR}=$ Mitral Regurgitation, $\mathrm{Yrs}=\mathrm{Years}, \mathrm{CAD}=\mathrm{Coro}-$ nary Artery Disease. 


\section{Results}

\section{Growth and Expansion}

Our center has been the regional VISN referral cardiac surgery center since 2001. Institution of our HVC began in 2006 with the coordination of a dedicated cardiothoracic surgeon and cardiologist. Since that time, the program has grown to support four cardiology and cardiothoracic physician assistants, an advanced cardiac imaging cardiologist, structural interventional cardiology attending, cardiology fellow, CT research fellow, database administrator, and nurse coordinator in conjunction with our transcatheter aortic valve replacement (TAVR) program (Figure 2).

Since 2006, 560 patients have been evaluated in HVC. Overall, new patient yearly volume has nearlytripled with now over 90 new consults seen yearly. Of the patients evaluated, 313 were referred for operative intervention with follow up post-operatively to affirm adequate post-procedural function. Following HVC referral trends, operative yearly volume has increased $33 \%$ over the last three years compared to the first three years of the program (Figure 3). The heart valve clinic has also matured to support a dedicated TAVR program.

Of the 12 TAVRs performed, there were no cases of 30-day mortality, stroke, MI, prosthetic valve endocarditis, or conversion to surgical aortic valve replacement (Table 3(a)). Heart failure class improved at 30 day follow up in all but one patient (Table $3(\mathrm{~b})$ ). On follow up analysis which was $100 \%$ complete, there were no deaths (mean duration $9.9 \pm 4.3$ months; range 3 - 17 months). Our outcomes highlight the importance of patient selection for TAVR within the context of a multidisciplinary care team with broad expertise and experience.

\section{Discussion}

The prevalence of HVD continues to increase with implementation of a Heart Valve Team as a well-recognized key component of optimal therapy, however the implementation of such structures are lacking. Several studies have demonstrated that despite clear guidelines, a large gap in actual practice of the Heart Valve Team continues to exist in both the United States and Europe [5] [6] [7].

To counter this treatment gap, Chambers et al. argues for "Heart Valve Centres of Excellence"-treatment centers including multidisciplinary teams with

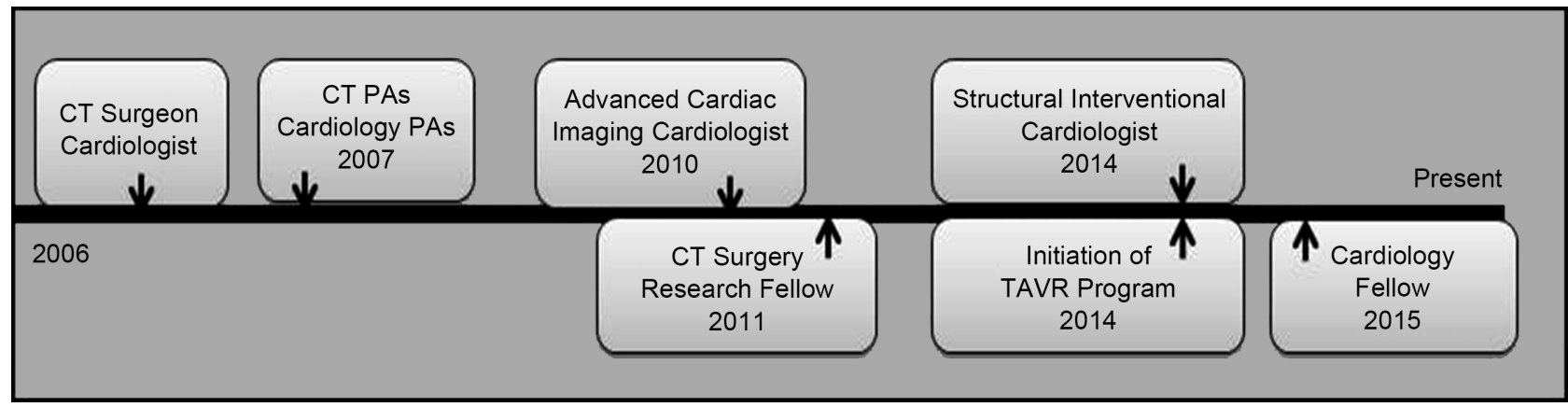

Figure 2. Timeline of HVC expansion. 


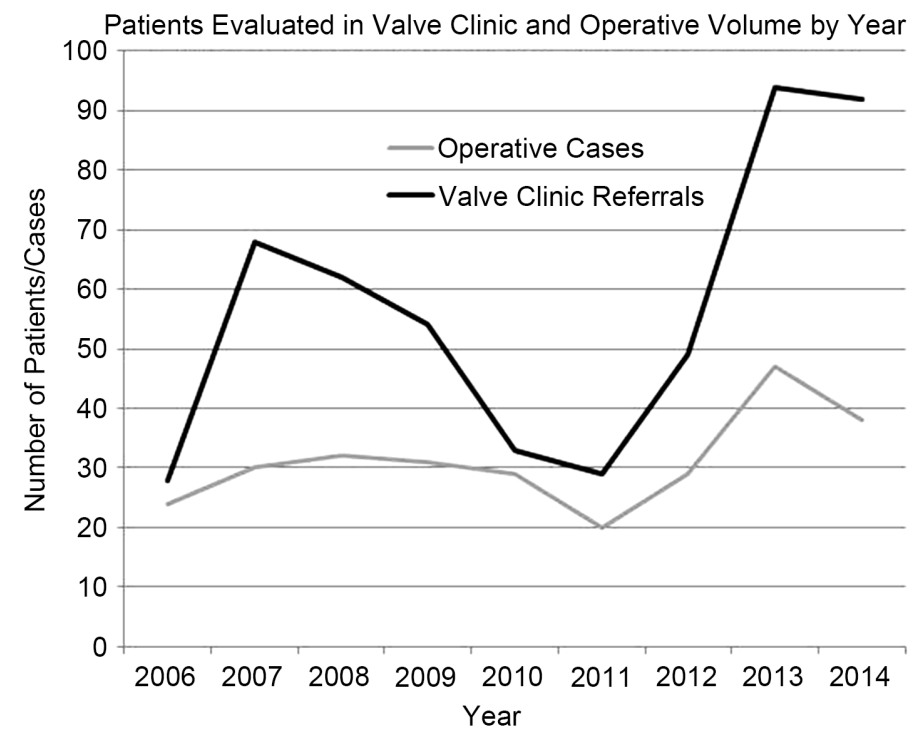

Figure 3. Increase in patients evaluated in valve clinic and operative volume over time.

Table 3. Clinical Outcomes of early TAVR Experience of program evolving from long standing valve clinic.

(a)

Conversion to open aortic valve replacement, No.

0

Myocardial Infarction, No.

Stroke, No.

0

Endocarditis, No.

0

Renal Failure requiring dialysis, No. 0

Paravalvular leak, No. (\%)

$\begin{array}{lc}\text { None } & 9(75) \\ \text { Trace } & 2(17) \\ \text { Mild } & 1(8)\end{array}$

Moderate

Required blood transfusion, No. (\%)

Post-op arrhythmias, No. (\%)

Readmission due to congestive heart failure, No. (\%)

Length of ICU stay, mean (SD) [range], hours

Length of Hospital stay, mean (SD) [range], days

$29(10.8)[20-50]$

Death within $30 \mathrm{~d}$, No.

$4.6(2.2)[3-9]$

0

Death, No

0

(b)

\begin{tabular}{cccc}
\hline Variable & Pre-operative mean & Post-operative mean & P value \\
\hline Ejection Fraction (EF) & $50.8 \pm 8.2$ & $54.7 \pm 12.5$ & $\mathrm{P}=0.06$ \\
Mean aortic gradient & $44.8 \pm 12.5$ & $11.8 \pm 9.5$ & $\mathrm{p}<0.001$ \\
Maximum aortic gradient & $72.5 \pm 18.5$ & $22.7 \pm 16.9$ & $\mathrm{p}<0.001$ \\
Heart failure class & & & $\mathrm{P}=0.002^{+} ; V=66$ \\
\hline
\end{tabular}

${ }^{+}$Paired Wilcoxon signed rank test with continuity correction. 
specialized expertise in imaging, clinical assessment, and surgery for patients with VHD [8]. Chambers asserts that this structured, training program overseen by national and international professional societies could affect improvement in surgical outcomes, particularly with mitral valve repair as rates of repair are higher with lower mortality in high volume centers. Lancellotti adds that in addition to Centres of Excellence, the use of national outcomes registries to improve adherence to national guidelines and ensure standards for best practice are essential in this model [9].

Designated referral centers of excellence are particularly important in the TAVR era. As described in our HVC model, the evolution of a TAVR program from HVC is a natural progression. An HVC approach leads to a more directed, time and cost-efficient work-up in the TVR patient as the multidisciplinary team approach ensures safe, appropriate, implementation of advancing therapy [10]. As indications for TAVR include lower risk patients and new centers offer therapy, implementation must continue to take place within a multidisciplinary team to ensure safe and appropriate application [11].

The first VA to publish TAVR results in 2013 established the safety and excellent outcomes of TAVR within a VAMC [12]. Our early outcomes echo their success in providing the Veteran population a much needed alternative to surgical AVR in the high risk patient. In the future, the structure of the VA system presents an opportunity for Veteran care models in particular the HVC to play a critical role in VHD treatment. As described by Kelly and Mudy, the VAMC TAVR experience is critical to understanding the future of this new technology [13]. Given the innate centralized care, database enrollment, and long-term follow up abilities, the VA is an ideal frontier for TAVR within an active and productive HVC.

\section{Conclusion}

As the options for heart valve therapy and indications for surgery continue to evolve, a multidisciplinary team to guide decision making is imperative. We present the success and growth of our heart valve clinic within a VAMC as a structural model that can be translated into both the community and academic setting.

\section{Acknowledgements}

We report no conflicts of interest. This material is the result of work supported with resources and the use of facilities at the Washington, DC VA medical facility. The contents do not represent the views of the US Department of Veterans Affairs or the United States Government.

\section{References}

[1] Nishimura, R.A., Otto, C.M., Bonow, R.O., Carabello, B.A., Erwin, J.P., Guyton, R.A., et al. (2014) 2014 AHA/ACC Guideline for the Management of Patients with Valvular Heart Disease: A Report of the American College of Cardiology/American 
Heart Association Task Force on Practice Guidelines. Journal of the American College of Cardiology, 63, e57-e185. https://doi.org/10.1016/j.jacc.2014.02.536

[2] Vahanian, A., Alfieri, O., Andreotti, F., Antunes, M.J., Barón-Esquivias, G., Baumgartner, H., et al. (2012) Guidelines on the Management of Valvular Heart Disease (Version 2012): The Joint Task Force on the Management of Valvular Heart Disease of the European Society of Cardiology (ESC) and the European Association for Cardio-Thoracic Surgery (EACTS). European Heart Journal, 33, 2451-2496.

https://doi.org/10.1093/eurheartj/ehs109

[3] Holmes, D.R., Rich, J.B., Zoghbi, W.A. and Mack, M.J. (2013) The Heart Team of Cardiovascular Care. Journal of the American College of Cardiology, 61, 903-907. https://doi.org/10.1016/j.jacc.2012.08.1034

[4] The Society of Thoracic Surgeons (STS) (2011) Statement before the Food and Drug Administration Circulatory System Devices Panel of the Medical Devices Advisory Committee. The Society of Thoracic Surgeons, Chicago.

[5] Iung, B., Messika-Zeitoun, D., Cachier, A., Delahaye, F., Baron, G., Tornos, P., et al. (2007) Actual Management of Patients with Asymptomatic Aortic Valave Disease: How Practice Fits With Guidelines. American Heart Journal, 153, 696-703. https://doi.org/10.1016/j.ahj.2005.12.031

[6] Lancellotti, P., Rosenhek, R. and Pibarot, P. (2014) Heart Valve Clinic: Rationale and Organization. Canadian Journal of Cardiology, 30, 1104-1107. https://doi.org/10.1016/j.cjca.2014.01.019

[7] Lancellotti, P., Rosenhek, R., Pibarot, P., Iung, B., Otto, C.M., Tornos, P., et al. (2013) ESC Working Group on Valvular Heart Disease Position Paper-Heart Valve Clinic: Organization, Structure, and Experiences. European Heart Journal, 34, 1597-1606. https://doi.org/10.1093/eurheartj/ehs443

[8] Chambers, J., Ray, S., Prendergast, B., Graham, T., Campbell, B., Greenhalgh, D., et al. (2015) Standards for Heart Valve Surgery in a "Heart Valve Centre of Excellence." Open Heart, 2, Article ID: e000216. https://doi.org/10.1136/openhrt-2014-000216

[9] Lancellottti, P., Dulgheru, R. and Sakalihasan, N. (2015) Centres of Excellence in Heart Valve Surgery: Are There Standards for Best Practice? Open Heart, 2, Article ID: e000282.

[10] Showkathali, R., Chelliah, R., Brickham, B., Dworakowski, R., Alcock, E., Deshpande, R., et al. (2014) Multi-Disciplinary Clinic: Next Step in "Heart Team" Approach for TAVI. International Journal of Cardiology, 174, 453-455. https://doi.org/10.1016/j.ijcard.2014.04.017

[11] Desai, C.S., Roselli, E.E., Svensson, L.G. and Bonow, R.O. (2013) Transcatheter Aortic Valve Replacement: Current Status and Future Directions. Seminars in Thoracic and Cardiovascular Surgery, 25, 193-196.

[12] Omer, S., Kar, B., Cornwell, L.D., Blaustein, A., Levine, G., Ali, N., et al. (2013) Early Experience of a Transcatheter Aortic Valce Program at a Veterans Affairs Facility. JAMA Surgery, 148, 1087-1093. https://doi.org/10.1001/jamasurg.2013.3743

[13] Kelly, R.F. and Mudy, K. (2013) The VA Advantage for Appropriate TAVR Use. JAMA Surgery, 148, 1093-1094. https://doi.org/10.1001/jamasurg.2013.3719 
Submit or recommend next manuscript to SCIRP and we will provide best service for you:

Accepting pre-submission inquiries through Email, Facebook, LinkedIn, Twitter, etc. A wide selection of journals (inclusive of 9 subjects, more than 200 journals)

Providing 24-hour high-quality service

User-friendly online submission system

Fair and swift peer-review system

Efficient typesetting and proofreading procedure

Display of the result of downloads and visits, as well as the number of cited articles Maximum dissemination of your research work

Submit your manuscript at: http://papersubmission.scirp.org/

Or contact wjcs@scirp.org 